\title{
The Development of Infant Monkeys Fed Low Phenylalanine Diets
}

\author{
George R. Kerr ${ }^{[49]}$, Arnold S. Chamove, Harry F. Harlow and Harry A.Waisman \\ Departments of Pediatrics and Psychology and the Regional Primate Research Center, \\ University of Wisconsin, Madison, Wisconsin, USA
}

\begin{abstract}
Extract
The nutritional adequacy of a commercial low-phenylalanine diet (Diet LF) has been investigated in infant rhesus monkeys. All animals were fed a control diet (Diet GD) during the first month of life. Thereafter, animals in Group A were fed LF until seventy-five days of age. This diet was then supplemented with $0.1 \mathrm{~g}$ of L-phenylalanine per kilogram of body weight until 105 days of age and with $0.2 \mathrm{~g}$ of L-phenylalanine per kilogram from 105 to 135 days of age. Animals in Group B were fed LF supplemented with an amount of L-phenylalanine equal to that contained in CD $(0.087 \mathrm{~g} / 100 \mathrm{ml})$ from 30 to 135 days of age. For the remainder of the first year of life, all animals were again fed CD. Animals in Group A developed growth failure, anemia, hypoproteinemia, dermatitis, edema, hypophenylalaninemia and elevated levels of several other free amino acids in serum when fed LF. The addition of supplements of L-phenylalanine corrected hypoproteinemia, hypophenylalaninemia, and anemia, but improvement of dermatitis and growth rates were not seen until the animals were again fed CD. Animals in Group B developed dermatitis and elevated levels of several of the free amino acids in serum. but showed no other biochemical or clinical evidence of phenylalanine deficiency. After one year of age, all animals were evaluated for learning behavior. There was a significant decrease in the learning ability of animals in Group A, while that of animals in Group B was comparable with that of control animals.
\end{abstract}

\section{Speculation}

Synthetic diets have been proposed as specific therapy for those inborn errors of metabolism that usually result in serious disability or death. Infant rhesus monkeys fed a commercial low-phenylalanine diet developed a syndrome of phenylalanine deficiency comparable with that which has been reported in some human infants fed the same diet. This study demonstrates the potential adverse effects of any diet deficient in essential nutrients and indicates that this subhuman primate may be of value in investigating the nutritional adequacy of other synthetic diets that may be proposed for use in children. 


\section{Introduction}

Diets deficient in protein or specific amino acids currently provide the only practical therapy for those inborn errors of amino acid metabolism that, unless treated, result in mental retardation or death [25]. While the benefits of such diets, in minimizing the potential damage to the central nervous system, are generally accepted $[2,9,36]$, inappropriate use has been reported to produce adverse effects and malnutrition in children $[1,3,4,7,13,15,16,22,27-31,37$, $39,41]$. The nutritional requirements for growth and the normal patterns of physical, biochemical, and behavioral development of several subhuman primates have been sufficiently established to indicate the usefulness of these species in studies related to human biology. In order to determine the value of these species in establishing the nutritional adequacy of synthetic diets that may be proposed for use in children with metabolic disorders, a commercial low-phenylalanine diet was investigated in infant rhesus monkeys.

\section{Materials and Methods}

Infant rhesus monkeys (Macaca mulatta) from fullterm, normal pregnancies were separated from their mothers within 6 hours after birth and transferred to individual, heated cages. For the remainder of the first 24 hours of life, the infants were fed a $10 \%$ glucose solution at four-hour intervals; during the second day, this diet was supplemented with equal volumes of a commercial milk preparation (control diet, CD) [42]. Thereafter, the infants were fed CD ad libitum at fourhour intervals for the first 30 days of life; this feeding schedule was continued for both control and experimental diets for the remainder of the first year. Daily supplements of vitamins [43] were provided after 3 days of age. Records were kept on dietary intake, body length, weight, head circumference, and signs of clinical health. In two animals, linear measurements were not obtained prior to initiation of the experimental diet.

Experimental Group A was composed of four animals fed a commercial low-phenylalanine diet (LF) [44] from 30-75 days of age. L-phenylalanine (Øal) [45] was then added to the deficient diet in amounts of $0.1 \mathrm{~g} / \mathrm{kg}$ body weight from 75 to 105 days of age and 0.2 $\mathrm{g} / \mathrm{kg}$ from 105 to 135 days of age. At 135 days of age, animals were again fed CD. Experimental Group B consisted of three test animals fed LF supplemented with an amount of $\varnothing$ al equal to that contained in $\mathrm{CD}$ $(0.087 \mathrm{~g} / 100 \mathrm{ml})$ from 30 to 135 days of age. Subsequently, these animals were also returned to $\mathrm{CD}$. The compositions of the diets CD and LF are indicated in table I. Control data on the free amino acids in serum was provided by a group of 10 normal infant monkeys fed $\mathrm{CD}$ ad libitum during the first year of life [23]. A group of 8 animals fed the same diet defined the normal rates of linear and weight growth. At 1 year of age, after receiving $\mathrm{CD}$ for a minimum period of 5 months in order to evaluate 'catch up' growth, the diet of all animals was changed to a commercial ration [46] to help evaluate learning performance.

Samples of venous blood were obtained at 2-week intervals while the animals were receiving the experimental diets. All samples were obtained four hours after a regular feeding. Hematologic data was obtained by standard clinical methods. Total proteins in serum were analyzed by a micro-Kjehldahl method [26]; after separation by micro-zone electrophoresis, individual proteins were analyzed on a Beckman/Spinco Analytrol. Following acidification and high-speed centrifugation of serum [17], the free amino acids were stored frozen and subsequently analyzed by the method of Spackman et al. [34] using a Beckman/Spinco automatic amino acid analyzer. An internal standard of $\beta$-2-thienylalanine was incorporated with each serum sample. Recovery of the standard in this series of experiments was $98.70 \pm 4.78 \%$ (mean \pm 1 standard deviation). Gystine and tryptophan were not evaluated because these amino acids are unstable during storage [11] and because of the potential errors that result from albumin-binding of tryptophan [17]. A decrease in glutamine and an increase in glutamic acid have been reported to occur coincident to prolonged storage of plasma samples [11]; although glutamine is also metabolized to compounds other than glutamic acid, values for these two amino acids were combined.

Three discrimination tests were used in evaluating the learning behavior of animals in each of the dietary groups [20]. The first test involved 20 object discrimination problems in which the monkey responded by displacing one of two objects covering food wells in a standardized Wisconsin General Test Apparatus [20]. The objects differed in multiple dimensions and a food reward was consistently placed under the same object. The monkey was required to identify and displace the correct object, irrespective of position. In the second test, 'staircase delayed response', the food reward was conspicuously placed in one of the two food wells, which were then covered with identical objects. After a delay interval, the monkey was required to remember and respond to the rewarded position. The delay interval increased in 5-second increments following two correct responses and decreased in 5-second increments subsequent to an error. Group comparisons were made at the maximum delay interval achieved. The final test, 'object discrimination learning set', involved an extended series of 500 object discrimination problems 
Table $I$. Composition of the experimental $\operatorname{diets}^{1}$

\begin{tabular}{|c|c|c|}
\hline & \multicolumn{2}{|c|}{$\begin{array}{l}\text { Approximate analysis } \\
\mathrm{g} / 100 \mathrm{~g} \text { powder }\end{array}$} \\
\hline & $\mathrm{CD}$ & LF \\
\hline Carbohydrate & 53 & 57 \\
\hline \multicolumn{3}{|l|}{ Protein } \\
\hline (or 'nitrogen equivalents') & 14 & 15 \\
\hline Fat & 27 & 18 \\
\hline Minerals & 4 & 5 \\
\hline \multicolumn{3}{|l|}{ Calories/fluid ounce } \\
\hline reconstituted diet & 20 & 20 \\
\hline \multicolumn{3}{|c|}{ Amino acid composition-mg/liter of final diet } \\
\hline & $\mathrm{CD}$ & $\mathrm{LF}$ \\
\hline Arginine & 630 & 510 \\
\hline Histidine & 400 & 390 \\
\hline Isoleucine & 1070 & 1125 \\
\hline Leucine & 1800 & 2115 \\
\hline Lysine & 1300 & 2355 \\
\hline Methionine & 440 & 675 \\
\hline Phenylalanine & 870 & 120 \\
\hline Threonine & 770 & 1155 \\
\hline Tryptophan & 250 & 285 \\
\hline Valine & 1150 & 1800 \\
\hline Cystine & 160 & 37 \\
\hline Alanine & 380 & 960 \\
\hline Aspartic acid & 820 & 2010 \\
\hline Glutamic acid & 3370 & 5670 \\
\hline Proline & 1240 & 1695 \\
\hline Serine & 790 & 1530 \\
\hline Tyrosine & 940 & 1215 \\
\hline Glycine & 60 & 525 \\
\hline
\end{tabular}

1 Data kindly provided by manufacturers.

using 6 trials per problem. Animals were compared with regard to performance on trial 2, trials 2 through 6 , and on maximal performance on trial 2 in each block of 100 problems. The significance of differences in learning behavior was ascertained by means of an unweighted unequal $\mathcal{N S}_{\mathrm{s}}$ analysis of variance, using the method of individual degrees of freedom.

\section{Results}

All animals demonstrated normal growth rates when fed CD during the first month of life. Although a change in taste was introduced with the experimental diets, the mean volume and caloric intake per $\mathrm{kg}$ of body weight was not reduced below that of the control group (fig. 1). Addition of Øal supplements did not noticeably alter dietary volume in either of the experimental groups. Despite this normal dietary intake, animals in Group A showed a cessation of weight gain within 10 days after being fed the Øal-deficient formula (fig.2). Provision of supplemental $\varnothing$ al at 75 and 105 days of age did not improve the rate of weight gain significantly, but a rapid gain in weight occurred when the animals were again fed the control diet. Measurements of body length and head circumference revealed a comparable arrest in linear growth, and a marked improvement was again apparent when the diet was later changed to CD (fig. 3). Animals in Group B demonstrated normal rates of weight and linear growth throughout the entire experiment (figs. 2 and 3 ).

Lethargy, anorexia, diarrhea, hair depigmentation, dermatitis, and edema developed in the animals in Group A when fed unsupplemented LF. Two of the four animals in this group became critically ill. For one animal, it was necessary to add Øal to the deficient diet earlier than planned; the $0.1 \mathrm{~g} / \mathrm{kg}$ and the $0.2 \mathrm{~g} / \mathrm{kg}$ supplements were added at 60 and 90 days of age, respectively. This animal died at 116 days of age without showing any clinical improvement other than a modest weight gain that probably reflected increased edema fluid. The primary cause of death was pneumonia; autopsy did not reveal other abnormalities. Addition of the $\varnothing_{\text {al }}$ supplements at the appropriate ages did not reverse clinical deterioration in the second animal, and CD was provided earlier than planned, at 107 days of age. It was necessary to feed CD for 20 days before clinical improvement occurred. The other two animals in Group A were less seriously debilitated; addition of the Øal supplements appeared to stop the progression of the clinical signs of malnutrition. These signs were not reversed, however, until the animals were again fed CD. Animals in Group B developed dermatitis, the only clinical evidence of malnutrition.

Hypoproteinemia, primarily reflecting reduced levels of albumin in serum developed within several weeks after initiation of unsupplemented LF (fig. 4). It

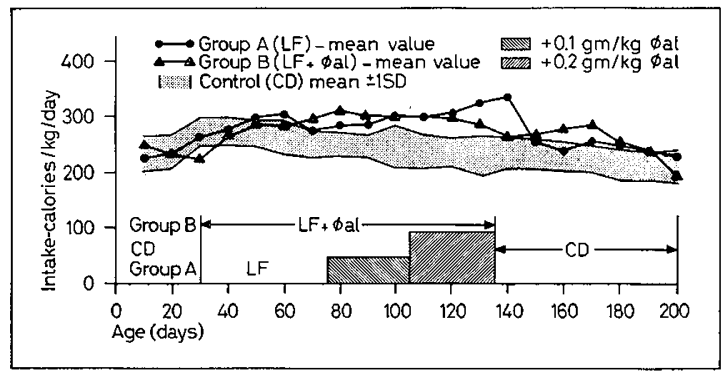

Fig. 1. Caloric intake/kg of body weight of infant monkeys fed control and experimental diets. 


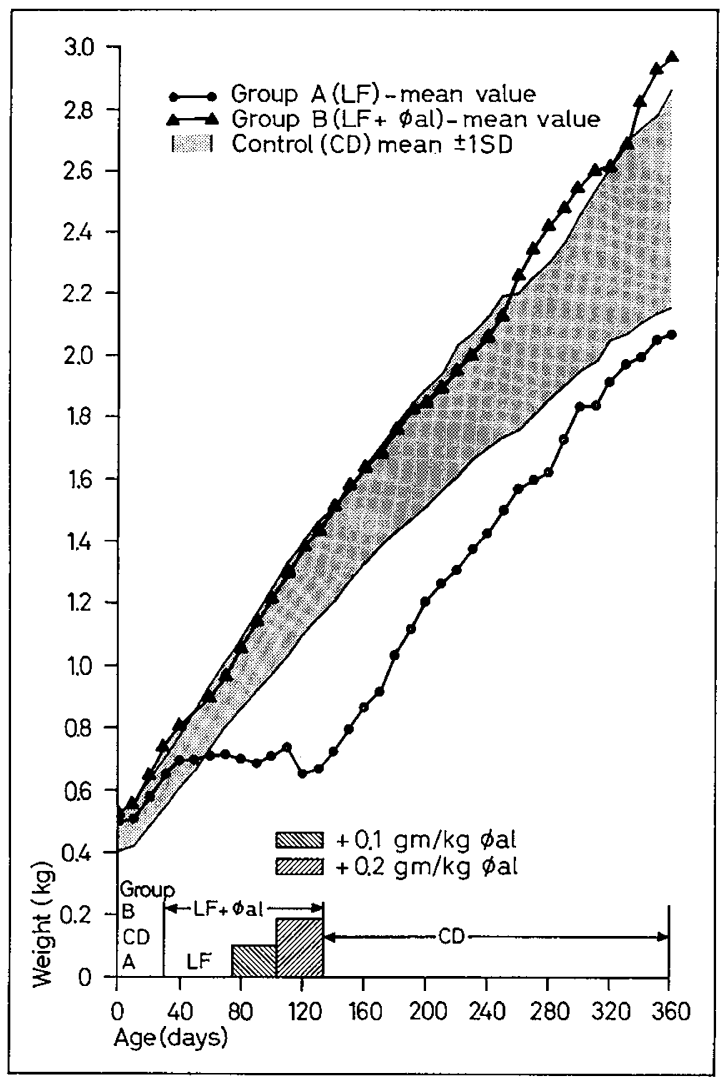

Fig. 2. The weight gain of infant monkeys fed the control diet (stippled area), the phenylalanine-deficient $\operatorname{diet}(\bullet-)$, and the deficient diet supplemented with L-phenylalanine $(\boldsymbol{\nabla}-\boldsymbol{\nabla})$.

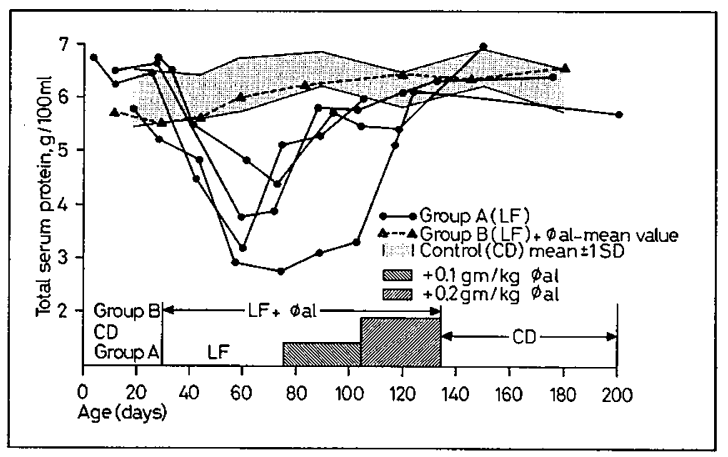

Fig.4. Total serum protein levels of infant monkeys fed the control diet (stippled area), the phenylalaninedeficient diet (-๑), and the deficient diet supplemented with L-phenylalanine $(\boldsymbol{\nabla}-\boldsymbol{\nabla})$.

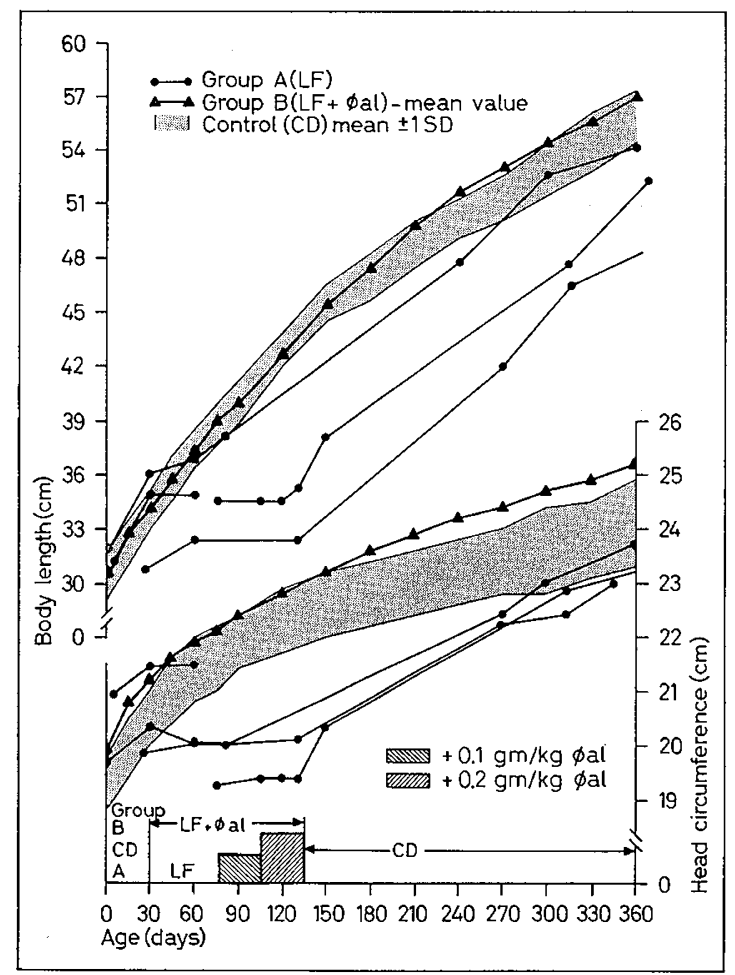

Fig. 3. The body length and head circumference of infant monkeys fed the control diet (stippled area), the phenylalanine-deficient diet $(-\bullet)$, and the deficient diet supplemented with L-phenylalanine $(\boldsymbol{\nabla}-\boldsymbol{\nabla})$.

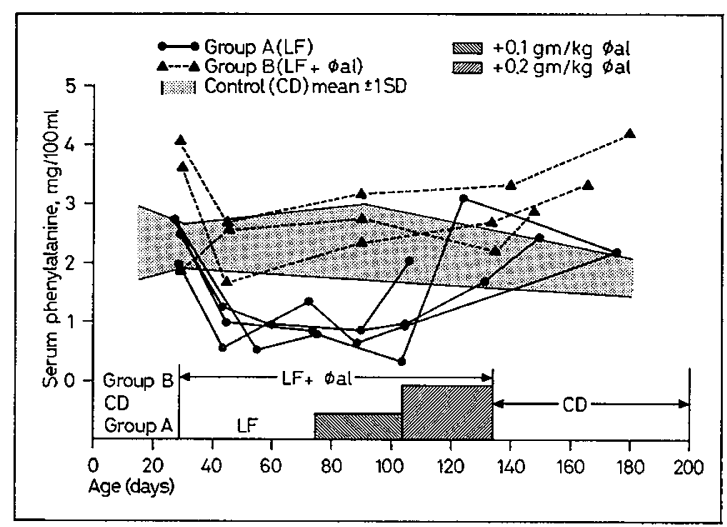

Fig. 5. Serum phenylalanine levels of infant monkeys fed the control diet (stippled area), the phenylalaninedeficient diet $(-\bullet)$, and the deficient diet supplemented with L-phenylalanine $(\boldsymbol{\nabla}-\boldsymbol{\nabla})$. 
was impossible to define consistent changes in the levels of other serum proteins. In contrast to the lack of apparent effect on physical growth, addition of the $0.1 \mathrm{~g} / \mathrm{kg} \varnothing \mathrm{al}$ supplement resulted in an immediate improvement in serum albumin levels; all animals showed normal levels of proteins in serum by the time the diet was changed to CD. In the animals in Group B, there were no significant changes in serum proteins throughout the study.

In both experimental and control groups, levels of free amino acids in serum exhibited a wide range of values for each amino acid, but certain trends were apparent. A marked reduction in levels of Øal (fig. 5) and tyrosine was consistently present during periods

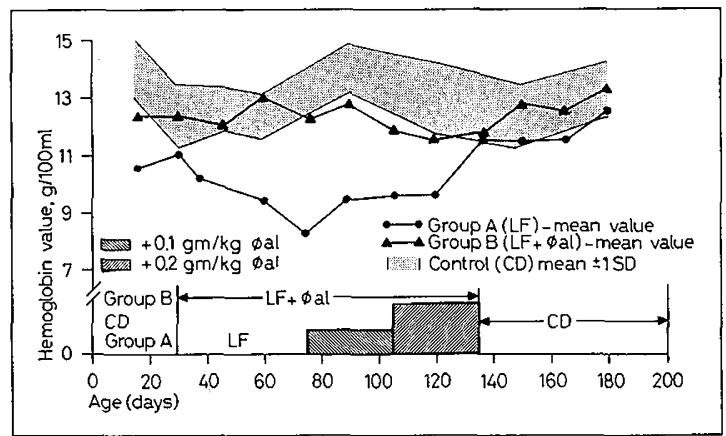

Fig.6. Hemoglobin values of infant monkeys fed the control diet (stippled area), the phenylalanine-deficient diet $(\bullet-)$, and the deficient diet supplemented with L-phenylalanine $(\boldsymbol{\nabla}-\boldsymbol{\nabla})$.

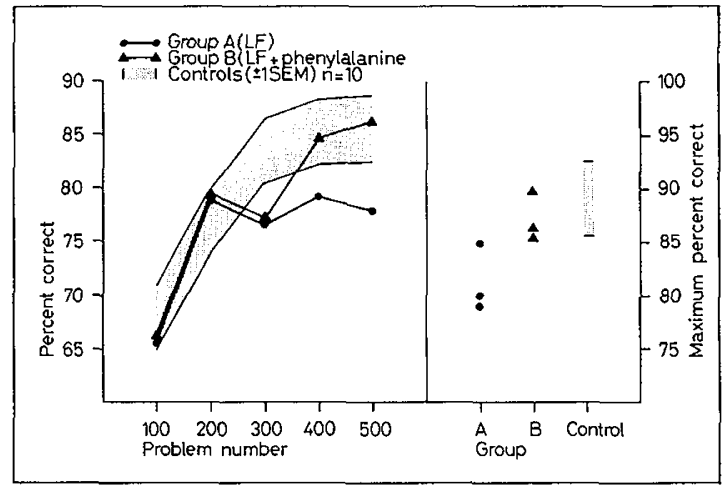

Fig.7. Trial 2 learning set performance of infant monkeys fed the control diet (stippled area), the phenylalanine-deficient $\operatorname{diet}(\bullet-)$, and the deficient diet supplemented with L-phenylalanine $(\boldsymbol{\nabla}-\boldsymbol{\nabla})$. The left side of the graph indicates the mean values of the experimental groups, and the right side indicates the maximum performance of the individual monkeys. when unsupplemented LF was consumed. The supplement of $0.1 \mathrm{~g} / \mathrm{kg} \varnothing \mathrm{al}$ improved the values for these two amino acids, but normal values were not attained in all animals until the $0.2 \mathrm{~g} / \mathrm{kg}$ supplement was provided. Low values were not noted for any of the other amino acids, but values for several, most notably serine, threonine, arginine, and glycine, were increased in the serum of animals in Group A. These amino acid levels tended to approach normal values when the $\varnothing$ al supplements were added to diet, and only levels of serine and threonine were significantly elevated by the time $\mathrm{CD}$ was again provided. Values for animals in Group B showed the same general patterns of change, with the exception that levels of $\varnothing \mathrm{al}$ in serum were not reduced. In addition to the amino acids previously mentioned, levels of leucine and lysine were also higher than levels in the serum of control animals.

Anemia became apparent within 2 weeks after initiation of LF; reticulocytosis and recovery occurred when $\varnothing$ al supplements were added (fig.6). Animals in Group B showed no significant hematological changes.

Object discrimination and delayed response tests revealed no significant differences in the learning behavior of experimental and control groups. Animals in Group A, however, were significantly less capable than were controls in learning set performance, using performance on trial $2(\mathrm{~F}=25.2, \mathrm{p}<0.001)$; trials $2-6$ $(\mathrm{F}=13.4, \mathrm{p}<0.01)$; and maximal performance on trial $2(\mathrm{~F}=29.0, \mathrm{p}<0.001)$ (fig. 7 ). The performance of animals in Group B was comparable with that of the control group.

\section{Discussion}

Phenylketonuria (PKU) is caused by a deficiency of the hepatic enzyme phenylalanine hydroxylase that converts $\varnothing$ al to tyrosine [24]. In the absence of this enzyme, $\varnothing \mathrm{al}$ and its metabolic by-products accumulate in blood and urine.

In an attempt to circumvent the potentially dangerous effects of hyperphenylalanemia, a synthetic diet containing enough $\varnothing$ al for synthesis of essential proteins, but not enough to produce hyperphenylalanemia, was introduced by BrakeL et al. in 1951 [6]. LF, the diet used in the present study, is available commercially. It is an enzymic hydrolysate of casein, which provides 'protein equivalents' in the form of peptides and amino acids. Øal is removed by absorption with charcoal, and the diet is then supplemented with methionine, tyrosine, tryptophan, minerals, vitamins, fats, and carbohydrates.

In a study utilizing a synthetic diet that contained a mixture of 18 amino acids as the source of nitrogen, 
SNyDERman et al. [32] concluded that the minimal daily $\emptyset$ al requirement for human infants was approximately $90 \mathrm{mg} / \mathrm{kg}$ of body weight. The clinical impression that only a narrow margin of safety separated the therapeutic reduction from the reduction that may give rise to symptoms and signs of deficiency has recently been substantiated by HanLey et al. [19]. They compared the physical and intellectual growth of two groups of infants with phenylketonuria. One group received 25-50 mg Øal/kg body weight/24 h; the other received a more liberal allowance of $75-150 \mathrm{mg} / \mathrm{kg}$ body weight $/ 24 \mathrm{~h}$. The latter group demonstrated a more normal developmental pattern. In a comparable study, Fisch et al. [16] reported that growth rates of children with phenylketonuria were less satisfactory when a low-Øal diet was prescribed than when no dietary management was attempted. Accordingly, unless carefully monitored, use of low-Øal diets, and presumably any synthetic diet, may result in significant developmental retardation.

The critical importance of adequate amounts of each of the essential amino acids for protein synthesis and growth has been confirmed by the present study. Although the caloric intake per $\mathrm{kg}$ body weight of animals receiving the deficient diet was equal to or greater than that of control animals, the rates of linear and weight growth were markedly abnormal in the former. This growth abnormality was prevented solely by addition of Øal, as demonstrated by the normal growth of animals in Group B. Hypoproteinemia, which developed in animals in Group A, was also prevented or corrected by addition of $\varnothing$ al to the deficient diet. Furthermore, since the dietary intake per $\mathrm{kg}$ body weight of hematopoietic trace elements and iron was identical in both groups, the finding that anemia developed only in animals in Group A indicates the relation between amino acid nutrition and the maintenance of normal hematological status.

Some factor other than Øal deficiency was responsible for the dermatitis that developed in all animals fed LF; this factor could not be identified by comparing the compositions of the two diets used. With this exception, however, and contrary to suggestions that a vitamin or choline deficiency is responsible for the malnutrition that may result from use of synthetic diets [39], it is apparent that the majority of the clinical problems associated with the low $\varnothing$ al diet used in the present study were prevented by the addition of $\varnothing$ al.

A wide variety of abnormalities in amino acid metabolism have been reported in conditions of 'protein malnutrition' in humans [14] and in experimental animals [10]. Under these conditions, plasma levels of free amino acids in humans are usually low for the 'essential' amino acids leucine, isoleucine, valine, lysine, and tyrosine, and are normal or elevated for the 'nonessential' amino acids [14, 21, 33]. Eventually, in the more serious cases, levels of all amino acids are low [21]. A different pattern of change was evident in the present study; although a wide range of values was found at each stage, the total value of all amino acids analyzed in both experimental groups was higher than the levels found in control animals. Most of the increase was ascribed to the nonessential amino acids, but levels of several of the essential amino acids were also elevated. The abnormalities in the levels of both essential and nonessential amino acids, and in the total value of all the amino acids analyzed, were largely corrected following addition of the $\varnothing$ al supplements.

An explanation for the elevation in levels of certain amino acids, at a time when levels of others were not significantly altered, is obscure; nor is it clear why addition to the diet of the single amino acid known to be deficient prevented malnutrition but did not prevent development of an abnormal pattern of free amino acids in serum. Although the amino acid composition of LF was quantitatively different from that of CD (table I), these differences do not entirely explain the discrepancies between the patterns of the free amino acids evident in the serum of animals under study.

Linear growth of children fails in conditions of protein malnutrition and may be unresponsive to subsequent establishment of optimum nutrition [18]. Of particular concern are the animal studies showing alterations in neurochemistry that accompany malnutrition early in life $[8,40]$ and the frequency with which early nutritional deprivation is associated with later behavioral disabilities in humans and rats [12, 35]. In the present study, all animals received the control diet for at least five months prior to evaluation of learning behavior; the significant decrease in learning ability, which was evident in the animals fed unsupplemented LF, suggests that a permanent disability had been produced by this diet.

The behavioral tests used in these experiments were designed to evaluate specific aspects of learning [20]. The 'object discrimination learning set' is the most informative, sensitive, and difficult test, measuring the capacity of the animals to improve sequentially the ability to solve object discrimination problems [38]. This test is sensitive to phyletic position, certain experimental lesions of the brain, and maturational changes. The data obtained from the animals in Group A fed LF demonstrated evidence of significant and permanent intellectual impairment. Performance of animals in Group B fed LF supplemented with Øal was not significantly different from that of the control group.

The values for free amino acids reported in the rhesus monkey are higher than those in the human [23]; it is apparent, however, that the $M$. mulatta infant shares with the human infant the potential for being adversely 
affected by a diet deficient in essential amino acids. In both species, malnutrition will inevitably follow the use of diets deficient in essential nutrients. Such diets may be evaluated usefully in infant rhesus monkeys prior to use in children with metabolic disorders.

\section{References and $\mathcal{N}$ otes}

1. Arakawa, T.; Hrrata, K. ; Ohara, K. ; Fujur, M.; TAKAhashi, Y. and Kato, H. : Folic acid deficiency due to a low-phenylalanine diet. Tohoku J.exp. Med. 87: 296-300 (1965).

2. Berman, P.W.; Waisman, H.A. and Graham, F.K. : Effectiveness of dietary treatment in Phenylketonuria: What is the proof? Develop. Med. Child Neurol. 9: 411-418 (1967).

3. Berry, H.K.; Sutherland, B.S.; Guest, G. M. and UMBarger, B.: Chemical and clinical observations during treatment of children with phenylketonuria. Pediatrics 21: 929-940 (1958).

4. Berry, H.K.; Umbarger, B. and Sutherland, B.S.: Procedures for monitoring the low-phenylalanine diet in treatment of phenylketonuria. $\mathrm{J}$. Pediat. 67: 609-616 (1965).

5. Berry, H.K. and Wright, S.: Conference on treatment of phenylketonuria. J.Pediat. 70: 142147 (1967).

6. Brakel, H.; Gerrard, J. and Hickmans, E. M.: The influence of phenylalanine intake on the chemistry and behavior of a phenylketonuric child. Acta pediat. scand. 43: 64-67 (1954).

7. Brimblecombe, F.S.W.; Blainey, J.D.; StoneMAN, M.E.R. and WooD, B.S.B.: Deitary and biochemical control of phenylketonuria. Brit. med. J. ii: 793-798 (1961).

8. Chase, H.P.; Dorsey, J. and McKhann, G. M.: The effect of malnutrition on the synthesis of a myelin lipid. Pediatrics 40: 551-559 (1967).

9. Glayton, B.; Moncrieff, A. and Roberts, G. E. : Dietetic treatment of phenylketonuria: a follow-up study. Brit.med.J. iii: 133-136 (1967).

10. Dean, W.F. and Scotr, H. M. : Use of free amino acid concentrations in blood plasma of chicks to detect deficiencies and excesses of dietary amino acids. J. Nutr. 88: 75-83 (1966).

11. Dickinson, J.C.; Rosenblum, H. and Hamilton, P.B.: Ion exchange chromatography of the free amino acids in the plasma of the newborn infant. Pediatrics 36: 2-13 (1965).

12. Dierks-Ventling, G.; Wapnir, R. A. and Braude, M.C.: Biochemical and behavioral effects of a commercial 'Low Phenylalanine' diet in growing rats. Proc. Soc. exp. Biol. N.Y. 127: 121-127 (1968).

13. Dodge, P.R.; Mancall, E.L.; Crawford, J.D.; Knapp, J. and Paine, R.S.: Hypoglycemia com- plicating treatment of phenylketonuria with a phenylalanine-deficient diet. New Engl.J.Med. 260: 1104-1111 (1959).

14. Edozren, J.C. and Obasr, M. E. : Protein and amino acid metabolism in kwashiorkor. Glin. Sci. 29: $1-24$ (1965).

15. Farber, S.; Vawter, G. F.: Clinical pathological conference. J. Pediat. 63: 667-675 (1963).

16. Fisch, R.O.; Gravem, H.J. and Feinberg, S.B.: Growth and bone characteristics of phenylketonurics. Amer. J. Dis. Child. 112: 3-10 (1966).

17. Gerritsen, T.; Rueberg, M.L. and Waisman, H. A. : On the determination of free amino acids in serum. Analyt. Biochem. 11: 460-466 (1965).

18. Graham, G. G. : Effect of infantile malnutrition on growth. Fed. Proc. 26: 139-143 (1967).

19. Hanlex, W.B.; Linsao, L. S.; Davidson, W. and Moes, G.A.F.: Malnutrition caused by dietary treatment of phenylketonuria. Pediat.Res. 2: 426-429 (1968).

20. Harlow, H.F.: The development of learning in the rhesus monkey. Amer. Sci. 47: 459-479 (1959).

21. Holt, L. E.Jr.; Snyderman, S. E.; Norton, P. M.; RoITMAN, J. and Finch, J. : The plasma aminogram in kwashiorkor. Lancet ii: 1343-1348 (1963).

22. Hsia, D. Y.-Y.; KNox, W.E.; Quinn, K.V. and PAine, R.S.: A one-year, controlled study of the effect of low-phenylalanine diet on phenylketonuria. Pediatrics 21: 178-201 (1958).

23. KERR, G. R.: The free amino acids of serum during development of $M$. mulatta. 1. During the first year of life. Pediat. Res. 2: 187-192 (1968).

24. Knox, W.E.: Phenylketonuria; in: The metabolic basis of hereditary disease (ed. Stanburry, J.B.; WyngaArden, J.B. and Fredrickson, D.S.), pp. 258-294 (McGraw-Hill, New York 1966).

25. Lowe, G. U.; Coursin, D. B. ; Heald, F. P. ; Holliday, M.A.; O’Brien, D.; Owen, G. M.; Pearson, H. A.; Sariver, G.R.; Filer, L.J., Jr. and Kline, O. L. : Nutritional management in hereditary metabolic disease. Pediatrics 40: 289-304 (1967).

26. Miller, G.L. and Miller, E.E.: Determination of nitrogen in biological materials. Analyt. Chem. 20: 481-488 (1948).

27. Moncrieff, A. and Wilkinson, R.H.: Further experiences in the treatment of phenylketonuria. Brit.med.J. i: 763-767 (1961).

28. Murdoch, M.M. and Holman, G.H. : Roentgenologic bone changes in phenylketonuria. Amer.J. Dis. Child 107: 523-532 (1964).

29. Pineda, G.: Variability in the manifestations of phenylketonuria. J. Pediat. 72: 528-530 (1968).

30. Rouse, B. M. : Phenylalanine deficiency syndrome. J.Pediat. 69: 246-249 (1966).

31. Royston, N.J.W. and Parry, T. E. : Megaloblastic 
anemia complicating dietary treatment of phenylketonuria in infancy. Arch. Dis. Childh. 37: 430435 (1962).

32. Snyderman, S.E.; Pratt, E.L.; Cheung, M.W.; Norton, P. and Holr, L.E., Jr.: The phenylalanine requirement of the normal infant. J. Nutr. 56: 253-263 (1965).

33. Snyderman, S.E.; Holt, L.E., Jr.; Norton, P.M.; Rottman, E. and Phansalkar, S.V.: The plasma aminogram. I. Influence of the level of protein intake and a comparison of whole protein and amino acid diets. Pediat. Res. 2: 131-144 (1968).

34. Spackman, D.H.; Stein, W.H. and Moore, S.: Automatic recording apparatus for use in the chromatography of amino acids. Anal. Chem. 30: 1190-1206 (1958).

35. Stoch, M. B. and Smythe, P. M. : Does undernutrition during infancy inhibit brain growth and subsequent intellectual development? Arch. Dis. Childh. 38: 546-552 (1963).

36. Sutherland, B.S.; Umbarger, B. and Berry, H.K.: The treatment of phenylketonuria. Amer. J. Dis. Child. 111: 505-523 (1966).

37. UMBARGER, B.: Phenylketonuria-treating the disease and feeding the child. Amer.J.Dis. Child 100: 908-918 (1960).

38. Warren, J.M.: Primate learning in comparative perspective; in Behavior in nonhuman primates (ed. Schrier, A. M.; Harlow, H.F. and StollNitz, F.), vol. 1, p. 249-281 (Academic Press, New York 1965).

39. Wilson, K.M. and Clayton, B.E.: Importance of choline during growth, with particular reference to synthetic diets in phenylketonuria. Arch. Dis. Childh. 37: 565-577 (1962).
40. Wrnick, M. and Noble, A.: Gellular response in rats during malnutrition at various ages. J. Nutr. 89: 300-306 (1966).

41. Woolf, I.; Griffiths, R.; Moncrieff, A.; CoATES, S. and Dillistone, F.: The dietary treatment of phenylketonuria. Arch. Dis. Childh. 33: 31-45 (1958).

42. Similac, Ross Laboratories, Columbus, Ohio. Prepared at the recommended dilution of 132 grams Similac powder per liter of diet.

43. Paladac, Parke, Davis, and Co., Detroit, Michigan; containing Vitamins $A, D, C, B_{1}, B_{2}, B_{6}, B_{12}$, Nicotinamide and Pantothenic Acid (0.3 ml daily).

44. Lofenalac, Mead Johnson and Company, Evansville, Indiana. Prepared at the recommended dilution of $150 \mathrm{~g}$ Lofenalac powder per liter of diet.

45. Nutritional Biochemical, Inc., Chagrin Falls, Ohio.

46. Purina Monkey Chow, Ralston Purina Co., St. Louis, Missouri.

47. The technical assistance of Messrs. James GampBELL and Guenther SCHEFfLer is gratefully acknowledged. The assistance of Dr. JAmEs Allen in performing the autopsy is also gratefully acknowledged. Mead Johnson and Company generously provided the Lofenalac, and Parke, Davis and Company provided the Paladac utilized in this study.

48. Supported in part by grant FR-00167 from the National Institutes of Health to the Wisconsin Regional Primate Research Center.

49. Requests for reprints should be addressed to: GeORGe R. KeRR, M.D. Department of Pediatrics, University of Wisconsin, Madison, Wisconsin 53706 (USA). 